\title{
Digital Archives: Towards the Next Step
}

\author{
Arian Rajh \\ Agency for Medicinal Products and Medical Devices / \\ Department of Information and Communication Sciences, \\ Faculty of Humanities and Social Sciences, University of Zagreb / \\ Highflott \\ Zagreb, Croatia \\ arian.rajh@halmed.hr
}

\begin{abstract}
Summary
The author discusses what has to be taken into account when designing or upgrading digital archives today. After specifying standards associated with archival functions, this article brings preliminary communication related to upgrading of digital archival system implemented in the Agency for Medicinal Products and Medical Devices in Croatia.
\end{abstract}

Key words: digital archives, METS, OAIS, PAIMAS, PAIS, PREMIS, transfer projects

\section{Introduction}

There are numerous organisations which have running systems for management of digital records and which are archiving their digital content. Many systems were developed according to Open Archival Information System (OAIS) reference specification, ${ }^{1}$ using its information model and implementing all or several of its functions. However, implementing just one standard and ignoring other affiliated standards ${ }^{2}$ leads to archiving capability fixed to an original digital environment. This misses the point of OAIS concept and its preservation function. In order to facilitate technology-independent long-term preservation function, as well as transfer and exporting to other and future environments, digital archiving should be harmonised with producer-archives interface methodology and functional and system-based archival standards. Digital records and their associated metadata are constantly evolving. Export of content should correspond to one or several metadata and packaging standards.

Most recent archival standards should be included in designs of new systems or in upgrade plans for existing archives. Organisations should fine-tune OAIS functions in previously developed OAIS-compliant digital archives so they

\footnotetext{
${ }^{1}$ ISO 14721:2012 Space data and information transfer systems - Open archival information system - Reference model

${ }^{2}$ ISO 20104:2015, ISO 20652:2006, ISO 13527:2010, ISO 16363:2012
} 
could support transfer projects to other OAIS environments. Some examples are transfers from public creators' digital archives to principal archival authorities' repositories, as well as other acquisitions performed by archival authorities.

\section{DAIS analysis, findings and plans for the future}

Digital Archival Information System is the digital archival system implemented in the Agency for Medicinal Products and Medical Devices (Zagreb, Croatia) during EU-funded IPA project "Preparations for eCTD and Implementation of DAIS" (9.2013-11.2014). ${ }^{3}$ Digital Archival Information System (DAIS) was developed according to OAIS information and functional models. Generic interoperability methods were added to DAIS in its EU-financed development phase in order to enable its communication with existing business applications. During annual upgrades between 2015 and 2017, or the second phase of upgrading software, system integration was reinforced by refining generic methods or creating additional methods and additional workflows. DAIS was connected with archival management system so it could enable archiving and archival description of digitised and digitally-born records; connected with DPU Scan Xino internal digitisation system; Quality management system etc. Implementation of internal digitisation in the Agency was done according to authenticity related requirement that included adding identity and integrity metadata and excluded software interpolation from the digitisation process. Archiving of digitally-born records in DAIS comes down to the declaration of a document as a record and its protection by the IBM FileNet Enterprise Records component, placing a record into the structure of creators' fonds and adding ISAD (G) archival description by the archival management system. ${ }^{4}$ Digitised records as archival information packages (AIPs) have their preservation description information metadata set up to be the properties of their content and AIPs are being additionally described in an archival sense in the same manner as conventional paper records. The archival description used in the Agency is based on ISAD $(\mathrm{G})$ and ISAAR $(\mathrm{CPF})^{5}$ standards so it can be formatted as EAD XML finding aid. ${ }^{6}$ Archived digitised records and digitally-born records are

\footnotetext{
${ }^{3}$ This project was financed by the European Union. The Agency for Medicinal Products and Medical Devices was the beneficiary of the Instrument for Pre-accession Assistance (IPA) programme. The project was implemented by Ericsson Nikola Tesla and AAM Management Information Consulting (author of this article was project manager for the beneficiary).

${ }^{4}$ ISAD (G): General International Standard Archival Description, 2nd ed., 2000. The Agency for Medicinal Products and Medical Devices is aware of changes in archival description. At this stage, the Agency is observing the development of the Records in Contexts standard.

${ }^{5}$ ISAAR (CPF): International Standard Archival Authority Record for Corporate Bodies, Persons and Families, 2nd ed. Ottawa, 2004.

${ }^{6}$ Besides archival description functionality, application "Centrix Pismohrana" or archival management system developed by IT company Omega Software has some additional and 116
} 
also being transferred from the active storage to the archival storage. Ingest function, developed in the framework of migration and ingest module of DAIS in the first phase, was automated for internally digitised records in the second software upgrade phase. Export function and preparations for transfer process were developed in the second phase. Export from DAIS is initiated by the archival management application, but the outcome is not harmonised with most recent standards. For the upcoming phase or cycle of DAIS upgrading, related to export and transfer functionalities, it is planned to keep the existing workflow and to adjust information packages or the outcome of this workflow to most recent standards. ${ }^{7}$

Further improvement should be done toward usage of metadata standards like Metadata Encoding and Transmission Standard (METS). METS is XML container for descriptive and administrative metadata, metadata about file groups, package structural map and associated executable behaviours. In its descriptive and administrative sections, it may contain pointers to external metadata. Harmonisation with METS could be done on a level of export of packages as their associated description - in other words, it should be possible to export AIPs as groups of digital objects with METS XML metadata.

DAIS system should be tested against ISO 16363 requirements by using customised self-auditing questionnaire. Harmonisation with ISO 16363 requires at least partial implementation of PAIMAS, PAIS and XFDU. PAIMAS is Producer-archives interface methodology abstract standard aiming to define relationships between producer and the archives or producer's archives and archival authority or any secondary archival environment in our case. It covers OAIS administration and ingest functions in parts of negotiating submission agreement and ingesting submissions. The PAIMAS process consists of four phases: preliminary phase, with feasibility checks, formal definition phase, which is further elaborated in PAIS standard, transfer phase and validation of submission information packages (SIPs) phase. SIPs - taken from the perspective of public archives as something submitted to public archives - are defined precisely according to PAIS standard. PAIS process consists of the creation of abstract SIP model, the creation of SIP model related to particular producer - public archives transfer project, the creation of SIPs and their transfer and validation. PAIS defines which data and metadata should be provided to archives and in which order. SIPs implementation is supported by using XFDU as packaging standard. (XFDU remained linked mostly to space agencies' domain to a greater extent

customised functionalities linked to archival description and description of a creator, e.g. computer generation of EAD-formatted finding summary inventory. Please see references, Rajh 2016.

${ }^{7}$ Team for this upgrade project will be assembled by of the archival unit and IT unit of the Agency for Medicinal Products and Medical Devices and Ericsson Nikola Tesla's solution manager, developers and testers. 
than other standards from OAIS family.) Besides the OAIS itself, the other standards from OAIS series should be implemented in the Agency for Medicinal Products and Medical Devices on the level of packages because the exportfor-transfer function was already built in DAIS and it is feasible to modify its output.

Besides harmonisation with ISO 16363 standard, with the holistic approach at the system level, PREMIS standard should be implemented on the same level, by defining repository entities in the organisation. ${ }^{8}$ After that, PREMIS should be implemented on the object level, by embedding PREMIS metadata into XML (e.g. METS XML). The Agency should define its PREMIS entities and their properties. The Agency's intellectual entities as single units would include case files, dossiers, databases and books. The Agency's stored objects would include representations and files. Agents, rights and events should be defined in the Agency's archival management manual also. At the end, this will enable additional self-auditing of adherence of DAIS to PREMIS requirements.

Table 1: Digital archive's lifecycle on the example of the Agency for Medicinal Products and Medical Devices

\begin{tabular}{|l|l|l|}
\hline \multicolumn{1}{|c|}{ Lifecycle phase } & \multicolumn{1}{|c|}{ Implementation } & \multicolumn{1}{c|}{ Quality measure } \\
\hline $\begin{array}{l}\text { 1st phase - development } \\
\text { of system and system } \\
\text { customisation }\end{array}$ & $\begin{array}{l}\text { development of digital archives based } \\
\text { on OAIS standard; establishing } \\
\text { communications with existing IT } \\
\text { islands; management of archived } \\
\text { digital records }\end{array}$ & $\begin{array}{l}\text { system level: } \\
\text { OAIS, } \\
\text { content level: PDF/A }\end{array}$ \\
\hline $\begin{array}{l}\text { 2nd phase - upgrade of } \\
\text { software modules and } \\
\text { functions }\end{array}$ & $\begin{array}{l}\text { strengthening communication and } \\
\text { interoperability with IT applications; } \\
\text { building new linked systems and } \\
\text { workflows }\end{array}$ & $\begin{array}{l}\text { software modules level, } \\
\text { e.g. forensic quality of } \\
\text { digitisation process }\end{array}$ \\
\hline $\begin{array}{l}\text { 3rd phase - upgrade of } \\
\text { system }\end{array}$ & $\begin{array}{l}\text { fine-tuning of OAIS functions and } \\
\text { harmonisation with additional } \\
\text { archival standards; management of } \\
\text { archived authenticated digital records }\end{array}$ & $\begin{array}{l}\text { system level: PAIMAS, } \\
\text { PAIS, XFDU, METS, } \\
\text { PDF/A, blockchain } \\
\text { technology }\end{array}$ \\
\hline
\end{tabular}

DAIS's preservation planning and archival storage functions are facilitated with an automated conversion of declared textual records into PDF/A- $1 \mathrm{~b}$ file format by using particular software. In order to enhance these OAIS functions, it will be necessary to develop internal LTP procedure for conversion from existing archival file formats to archival file formats of next generations.

Besides OAIS ecosystem upgrade requirement, the examined records creator is using electronic signature solution valid only for internal purposes. It will be necessary to adopt the present-day "non-paper" concept of authenticity in the digital environment and to implement a solution which will be easier to maintain and which will be valid outside Agency's boundaries. Regarding obtaining

${ }^{8}$ PREMIS Data Dictionary for Preservation Metadata, http://www.loc.gov/standards/premis/ 
authenticity of records for the long-term, a substitute of original e-signatures by blockchain technology should be considered. ${ }^{9}$

\section{Conclusion}

Digital archives have their lifecycle as any software and hardware do and upgrades on the level of their parts (modules) or entire systems should be anticipated. Croatian Agency for Medicinal Products and Medical Devices carried out several upgrade 2 nd phase projects (Table 1) on system modules and functions level after finishing system development. It is very important to plan long-term preservation procedures related to internal conversions/migrations and transfers to external environments, as digital objects and their storage or digital archives are becoming technologically obsolete legacy systems. To be able to move organisational content to tomorrow's digital archives, it is necessary to plan transfer projects according to additional OAIS standards and other archival standards. Preservation cycles should, therefore, include projects in one OAIS system and transfers of packages between different OAIS-compliant systems. Although it is expected to use current technologies for archives management, the goal is to go beyond these technologies and to focus on the preservation function.

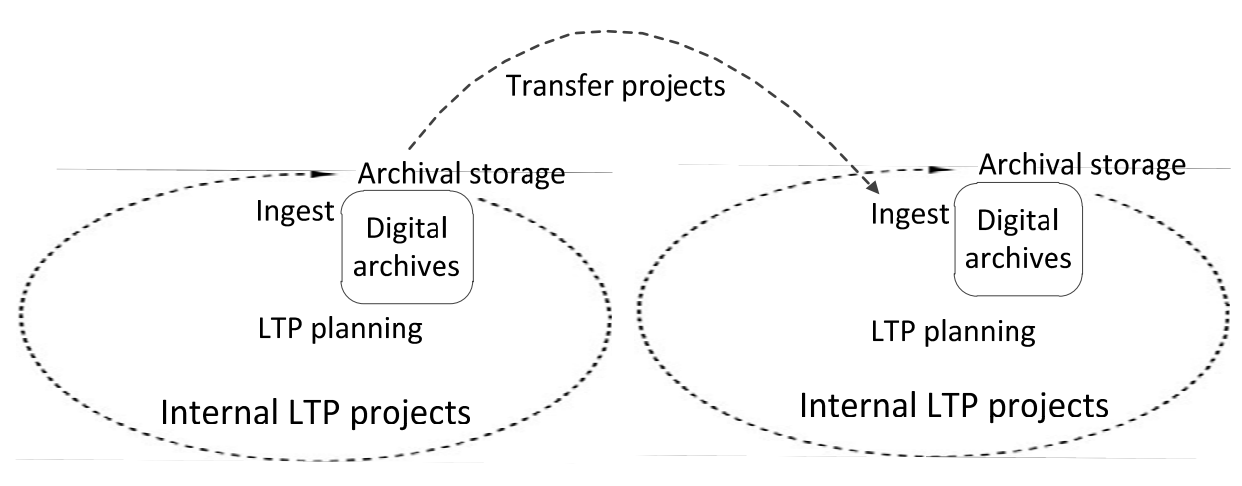

Figure 1: Digital content preservation cycles - a view through OAIS glasses

\footnotetext{
${ }_{9}^{9}$ Among other choices, please see Blanchette (2006) and Stančić (2016) from references.
} 


\section{References}

Blanchette, J.-F. The digital signature dilemma. // Annales des Télécommunications, 61

(7-8), 2006, 908-923. http://polaris.gseis.ucla.edu/blanchette/papers/annals.pdf (February 2017)

ICA. ISAD $(G)$ : General International Standard Archival Description, 2nd ed. 2000

ICA. ISAAR(CPF) International Standard Archival Authority Record for Corporate Bodies, Persons and Families, 2nd ed. 2004

ICA. ISDF International Standard for Describing Functions, 2011

ICA. ISDIAH International Standard for Describing Institutions with Archival Holdings, 2011

ICA. Records in Contexts CM. Consultation Draft v.01, September 2016

ISO 14721:2012 Space data and information transfer systems - Open archival information system - Reference model

ISO 20104:2015 Space data and information transfer systems - Producer-Archive Interface Specification (PAIS)

ISO 20652:2006 Space data and information transfer systems - Producer-archive interface Methodology abstract standard (PAIMAS)

ISO 13527:2010 Space data and information transfer systems - XML formatted data unit (XFDU) structure and construction rules

ISO 16363:2012 Space data and information transfer systems - Audit and certification of trustworthy digital repositories

METS, http://www.loc.gov/standards/mets/ (February 2017)

PREMIS Data Dictionary for Preservation Metadata, http://www.loc.gov/standards/premis/ (February 2017)

Rajh, Arian. Različite okoline, ista struka: mogućnosti primjene informatičke tehnologije u arhivima za izradu računalno generiranih opisa gradiva. // Arhivski vjesnik. 59 (2016), 1; 99116.

Stančić, Hrvoje. Long-term Preservation of Digital Signatures // Technical and field related problems of traditional and electronic archiving / Gostenčnik, Nina (ur.). Maribor: Pokrajinski arhiv, 2016. 481-491 